\title{
Caution Is Needed in Quantifying Terrestrial Biomass Responses to Elevated Temperature: Meta-Analyses of Field-Based Experimental Warming Across China
}

\author{
Kai Yan ${ }^{1,2}$, Shuang Zhang ${ }^{3}$, Yahuang Luo ${ }^{2}$, Zhenghong Wang ${ }^{2}$, Deli Zhai ${ }^{2}$, Jianchu Xu ${ }^{2,4, *}$, \\ Huizhao Yang ${ }^{2}$ and Sailesh Ranjitkar ${ }^{2,4}$ \\ 1 College of Resources and Environment, Yunnan Agricultural University, Kunming 650201, China; \\ ecoyankai@126.com \\ 2 Key Laboratory for Plant Diversity and Biogeography of East Asia, Kunming Institute of Botany, \\ Chinese Academy of Sciences, Kunming 650201, China; luoyahuang@mail.kib.ac.cn (Y.L.); \\ wangzhenghong@mail.kib.ac.cn (Z.W.); zhaideli@mail.kib.ac.cn (D.Z.); yanghuizhao@mail.kib.ac.cn (H.Y.); \\ sailesh@mail.kib.ac.cn (S.R.) \\ 3 State Key Laboratory of Urban and Regional Ecology, Research Center for Eco-Environmental Sciences, \\ Chinese Academy of Sciences, Beijing 100085, China; shuangzhang@rcees.ac.cn \\ 4 World Agroforestry Center, ICRAF East and Central Asia, Kunming 650201, China \\ * Correspondence: jxu@mail.kib.ac.cn; Tel./Fax: +86-871-65223377
}

Received: 5 August 2018; Accepted: 26 September 2018; Published: 9 October 2018

check for updates

\begin{abstract}
Certainty over warming-induced biomass accumulation is essential for addressing climate change. However, no previous meta-analysis has investigated this accumulation across the whole of China; also unclear are the differences between herbaceous and woody species and across plant phylogeny, which are critical for corresponding re-vegetation. We extracted data from 90 field-based experiments to reveal general patterns and driving factors of biomass responses all over China. Based on traditional meta-analyses, a warmer temperature significantly increased above- $(10.8 \%)$ and below-ground $(14.2 \%)$ biomass accumulation. With increasing warming duration $\left(\mathrm{Warm}_{\mathrm{D}}\right)$ and plant clade age, both above-ground and below-ground biomass showed significant increases. However, for herbaceous versus woody plants, and the whole community versus its dominant species, responses were not always constant; the combined synergies would affect accumulative response patterns. When considering Warm ${ }_{D}$ as a weight, decreases in total above-ground biomass response magnitude were presented, and the increase in below-ground biomass was no longer significant; notably, significant positive responses remained in tree species. However, if phylogenetic information was included in the calculations, all warming-induced plant biomass increases were not significant. Thus, it is still premature to speculate whether warming induces biomass increases in China; further long-term experiments are needed regarding phylogeny-based responses and interspecies relations, especially regarding woody plants and forests.
\end{abstract}

Keywords: above-ground biomass; below-ground biomass; meta-regression; phylogenetic meta-analyses; warming duration; plant clade age; herbaceous versus woody species

\section{Introduction}

Climatic warming is a major driver of change, considerably affecting global carbon (C) sequestration in various terrestrial ecosystems [1-3]. Quantifying the plant biomass response to warming is an important aspect of understanding global warming influences on the terrestrial biosphere and vegetation management under climate change $[4,5]$. Recently, investigations into 
the potential impacts of heating on grasslands and forests using warming experiments are increasing worldwide [6].

However, it remains a debated issue whether herbaceous and/or woody species would benefit from increased temperatures $[4,5]$. It is therefore hard to forecast the warming-induced vegetation responses and $\mathrm{C}$ sequestration across systems, in particular, forests where there is high diversity and which still play key roles in the global C balance. On our planet, there are more than 300,000 terrestrial plant species and great variations in their growth environments; a process of meta-analysis has become a suitable solution for investigating the general tendency of warming impacts $[4,7,8]$. To date, several meta-analyses have been carried out, indicating that elevated temperatures lead to overall accelerating biomass growth (both above-ground and below-ground) [4,5,9]. However, as of yet, no previous study has investigated this biomass accumulation across the whole of China. It is our opinion that a systemic review of corresponding field-based works and the conduct of meta-analyses form an essential aspect of addressing climate change and consequent re-vegetation in China.

Generally, previous (traditional) meta-analyses found that warming-induced biomass patterns varied among ecosystems and plant types. Specifically, biomass increases for seed plants due to warming were significantly higher than those for spore plants, increases for evergreen shrubs were greater than those for deciduous shrubs, and woody plants exhibited greater increases than herbaceous plants $[4,9]$. All these results not only show the importance of functional types in affecting the biomass response, but also indicate plant phylogenetic features and clade age to be key factors contributing to warming-induced biomass change. In 2012, Chamberlain et al. [10] re-analyzed 30 published meta-analyses and stated that traditional meta-analytic approaches lacked independence because of species with shared evolutionary histories, and the incorporation of phylogenetic information in ecological meta-analyses is important. Indeed, a growing number of scholars have suggested that considering phylogenetic features (phylogenetic signal, clade age, etc.) in meta-analysis could avoid the possible confounding effects of phylogeny on the results [10-12]. However, these above-mentioned concerns remain limited in the estimation of warming-induced biomass responses in China.

Moreover, some other factors also affect the quantification of results, which then do not necessarily show genuine feedback from nature and hinder future vegetation management. First, some previous works could have overrated the positive responses of biomass accumulation, as they include data from environment-controlled chamber experiments, which would reduce adverse effects from long-term warming, e.g., drought, C loss, and consequent interspecific relationships $[4,13,14]$. Second, little previous research has studied the differences in response from the whole plant community and its dominant species. We have mentioned that plant types, phylogenetic features, and consequent adaptive strategies could lead to variations in the biomass response to warmer climates [15], and notably, community structures could also be changed [16]. Thus, in contrast to general biomass at the community-level, more attention needs to be paid to the relationships of community-level biomass and the trade-off with its dominant species, which could benefit re-vegetation management [17]. Third, it is still a debated question whether warming duration (the length of the experiment) could affect warming-induced cumulative biomass change: If we include this factor as a weight in the meta-analysis approach, would it lead to changes in accumulative responses $[4,8,18]$ ? Certainty over this issue would enhance our understanding regarding long-term warming, and enhance the credible projection of climate-terrestrial $C$ feedback.

Therefore, in this study, we compiled data from 90 field-based experiments across the whole of China, and analyzed the documented dataset using hierarchical mixed models and phylogenetic meta-analyses. We tried to understand, first, the general pattern of the plant biomass response to warming in China (using a traditional approach). Second, we synthesized the warming duration and plant phylogenetic feature to be key drivers to warming-induced biomass accumulation. Third, we tested whether plant types (herbaceous versus woody species), the different responses of the plant community and its dominant species, and the combined synergies would affect biomass accumulation patterns. Fourth, we examined the changes in warming-induced accumulative biomass accumulation 
all over China, with added considerations of warming magnitudes, duration, and plant phylogenetics in the quantifying model. Our research could enhance evaluations of the potential impacts of climatic warming in China, and give rational suggestions for future studies, such as restorations of forests, grasslands, and their transitional zones where there is climatic warming.

\section{Materials and Methods}

\subsection{Data Collection}

We conducted surveys of articles published before January 2018 using the Web of Science and the China National Knowledge Infrastructure. Keywords used in the literature survey included 'plant biomass', 'plant community', 'plant growth', 'increased temperature', and 'warming' (see Supplementary Material, S1). Our analysis included literature on studies conducted in China: Only field experiments which focused on responses of terrestrial plants, above-ground biomass (AGB), and/or below-ground biomass (BGB); and responses of the plant community and/or its dominant species, were included. Altogether, we documented 90 publications-67 in Chinese and 23 in English-that fitted our criteria (see Supplementary Material, S2).

We recorded the following information from selected publications: latitude, longitude, elevation, mean annual temperature (MAT), mean annual precipitation (MAP), warming method, warming magnitudes (Delta ${ }_{\mathrm{T}}$ ), and monthly calculations of warming duration (Warm $\left.\mathrm{D}_{\mathrm{D}}\right)$. AGB and BGB, means $(\mathrm{X})$, standard errors (SE), standard deviations (SD), and sample sizes of both the control and warming treatments were properly tabulated. Dominant species in each plant community (mixed or mono) were compiled, based on which communities were separated into different plant functional types (PFTs), including Forb, Grass, Shrub, and Tree. All raw data were either obtained from tables or extracted by digitizing graphs using the GetData Graph Digitizer (version 2.24, Russian Federation, http:/ / getdata-graph-digitizer.com).

To examine the effects of warming facilities, we grouped warming facilities by passive heating (i.e., open-top chamber) and active heating (including electric heating cable and infrared heater) (see Supplementary Material, S3). Given that no impact of the warming facility on biomass responses of terrestrial plants to warming was detected through pre-analysis, experiments using different warming facilities were combined in this analysis.

\subsection{Statistical Analysis}

We followed the method described in Lin et al. [4] and Adams [11] for data analysis. In brief, we used different models such as traditional mixed-effects meta-regression models, hierarchical mixed effects meta-analyses, and phylogenetic meta-analyses to address our topics $[4,7,10,11]$. The natural log-transformed response ratios (RRs) of plant biomass at an increased temperature ( $\mathrm{Xi}$ ) to that at ambient temperature $\left(X_{c}\right)$ were calculated at the end of experiment, and consequently used to calculate the effect of warming treatments (Equation (1)) [4]. As required in the analysis, SE values in some of the literature were converted into SD. The variance of RRs (v) was approximated using Equation (2), where $S_{c}^{2}$ and $S_{i}^{2}$ are the standard deviations in the control and warming treatments, $n_{c}$ and $n_{i}$ are the sample sizes in control and warming treatments, and RRs is the only dependent variable throughout the analysis procedure in this research.

$$
\begin{gathered}
\text { LnRRs }=\operatorname{Ln}\left(\frac{X_{i}}{X_{c}}\right)=\operatorname{Ln} X_{i}-\operatorname{Ln} X_{c} \\
v=\frac{S_{i}^{2}}{n_{i} X_{i}^{2}}+\frac{S_{c}^{2}}{n_{c} X_{c}^{-2}}
\end{gathered}
$$

First, to quantify the general pattern of plants' biomass response to warming in China, cumulative effect sizes were calculated using hierarchical mixed models. The models took into account the 
hierarchical dependence in our data due to cases where multiple observations (i.e., effect sizes) were obtained from the same monitoring site and study. Before all analyses, we explored the possibility of publication bias using a funnel plot and calculated the fail-safe number. To make our results comparable with previous research $[4,8]$, traditional meta-analyses (1/v weights) based on different PFTs subsets were calculated (in R with the default "metafor" package) [19]. The warming effects were significant if the $95 \%$ confidence intervals (CI) of the cumulative effect size did not overlap with zero. The results are reported as RRs and as percentage changes by back-transforming RRs to ratios in the original scale (Equation (3)).

$$
\text { Percentage changes }=(\exp (\mathrm{RRs})-1) \times 100 \%
$$

To address our second topic, mixed-effects meta-regression models were used, in which both monitoring sites and study IDs were included as random effects ( 1 I site, 1 I ID). Parameters included latitude, longitude, elevation, MAT, MAP, Delta ${ }_{\mathrm{T}}$, Warm $_{\mathrm{D}}$, and plant clade age (Plant $\mathrm{CA}$ ). Regarding those variables, we tested the multicollinearity and rescaled them for normalization, before calculations. Plant $_{C A}$ values used here were based on techniques described in detail by Qian and Jin [20]. Afterwards, we used the Akasike Information Criterion (AIC) to select the best model from the proposed set of models (Table 1 has shown the best models for AGB and BGB, respectively). Analysis was carried out using the R package "glmulti" [21].

Table 1. Model-averaged coefficients, standard errors (SE), z-tests, and $p$-values for parameters which were included within the final (best) model sets for above-ground biomass (AGB) and below-ground biomass (BGB).

\begin{tabular}{cccccccccc}
\hline & \multicolumn{3}{c}{ Above-Ground Biomass (AGB) } & \multicolumn{3}{c}{ Below-Ground Biomass (BGB) } \\
\hline & Estimate & $\mathbf{S E}$ & $\mathbf{z}$ & $\boldsymbol{p}$ & Estimate & $\mathbf{S E}$ & $\mathbf{z}$ & $\boldsymbol{p}$ \\
\hline (Intercept) & -0.19 & 0.10 & -1.83 & 0.07 & 0.27 & 0.53 & 0.50 & 0.62 \\
Elevation & 0.07 & 0.05 & 1.51 & 0.13 & na & & & \\
Latitude & na & & & & -0.39 & 0.33 & -1.16 & 0.24 \\
Longitude & na & & & & 0.30 & 0.18 & 1.69 & 0.09 \\
MAT & 0.08 & 0.08 & 1.04 & 0.30 & 0.02 & 0.14 & 0.13 & 0.90 \\
MAP & na & na & na & na & -0.44 & 0.32 & -1.36 & 0.17 \\
Plant & & 0.05 & 0.01 & 13.01 & $<0.01$ & 0.17 & 0.01 & 16.02 & $<0.01$ \\
Warm $_{\mathrm{D}}$ & 0.10 & 0.02 & 6.13 & $<0.01$ & 0.19 & 0.02 & 8.66 & $<0.01$ \\
Delta $_{\mathrm{T}}$ & 0.11 & 0.01 & 11.04 & $<0.01$ & na & & & \\
Warm $_{\mathrm{D}}:$ Delta $_{\mathrm{T}}$ & -0.09 & 0.02 & -5.67 & $<0.01$ & na & & & \\
\hline
\end{tabular}

Estimate: slope of linear equation; MAT: mean annual temperature; MAP: mean annual precipitation; Plant ${ }_{\mathrm{CA}}$ : plant clade age; Warm ${ }_{D}$ : warming duration; Delta ${ }_{T}$ : warming magnitudes; na: parameters not included in the best models corresponding to AGB and BGB.

Last, to study the relationships between plant phylogenetic features, Delta ${ }_{T}$, Warm ${ }_{D}$, and the differences between the community as a whole (Biomass $\mathrm{CW}$ ) and its dominant species (Biomass $\mathrm{DS}_{\mathrm{DS}}$ ), we carried out two-step analyses. The dataset was separated into two subsets, corresponding to Biomass $_{\mathrm{CW}}$ and Biomass ${ }_{\mathrm{DS}}$, and then mixed-effects meta-regression models were used to compare the different responses of AGB and BGB. Regarding the results of the last section, Delta ${ }_{\mathrm{T}}$, Warm $\mathrm{D}_{\mathrm{D}}$, and plant clade age were key drivers in the dynamics of plant biomass. Therefore, effect sizes were re-calculated with weighting based on Delta ${ }_{T}$ and Warm ${ }_{\mathrm{D}}$, following details in Crowther et al. (Equation (4)) [14], where Rep $\mathrm{N}_{\mathrm{N}}$ and Study $\mathrm{N}_{\mathrm{N}}$ represent the number of repeats and observations within a study, respectively. Meanwhile, following the method described in Adams [11], the phylogenetic feature was included in the updated model. In total, there were 108 vascular plant species included in our analyses; first, we created phylogenetic trees with branch lengths (see Supplementary Material, S4) using the data from http:/ / phylodiversity.net/phylomatic/pmws, and phylogenetic meta-analyses were then launched 
using the phylogenetic signal and Clade age (phylogeny) data. For other details of the analysis, please check the R code in the Supplementary Material (S5).

$$
\text { Percentage changes }=(\exp (\mathrm{RRs})-1) \times 100 \%
$$

\section{Results}

\subsection{Plant Biomass Responses to Warming and the Varied Pattern among PFTs}

In this research, 523 observations for AGB and 155 observations for BGB were collected, respectively. Regarding our data sets, more herbaceous (AGB: 464, BGB: 120) than woody species data (AGB: 59, BGB: 35) were collected. Meanwhile, a large part of the observations was located only around the Inner Mongolian plateau and the Qinghai-Tibetan plateau. Thus grasslands have gotten more attention, while for other systems, e.g., forests, little research has been completed to date (Figure 1). For the results of traditional meta-analyses, in general, experimental warming significantly increased AGB by $10.8 \%(p<0.01)$ across all the plants and communities included (Figure 2$)$. Warming effects showed a strong dependence upon PFTs: The AGB response to the warming of woody plants $(+33.3 \%, p<0.01)$ was significantly greater than that of herbaceous plants $(+6.8 \%)$, whose $95 \% \mathrm{CI}$ overlapped with zero. Both forb and grass did not change, and no difference in the AGB response was detected between these two categories $(p>0.01)$. For BGB, a significant increase $(+14.2 \%)$ was observed across all the plants included (Figure 1) and its pattern also varied among PFTs, similar to the AGB trend. For woody plants, both trees $(+44.9 \%, p=0.01)$ and shrubs $(+27.1 \%, p=0.02)$ showed significant BGB increases under warming treatments. However, for herbaceous plants (Grass and Shrub), no difference in the BGB response was detected. Overall, experimental warming significantly increased plant biomass (AGB and BGB); woody plants in particular showed significantly greater accelerative biomass accumulation than herbaceous plants.
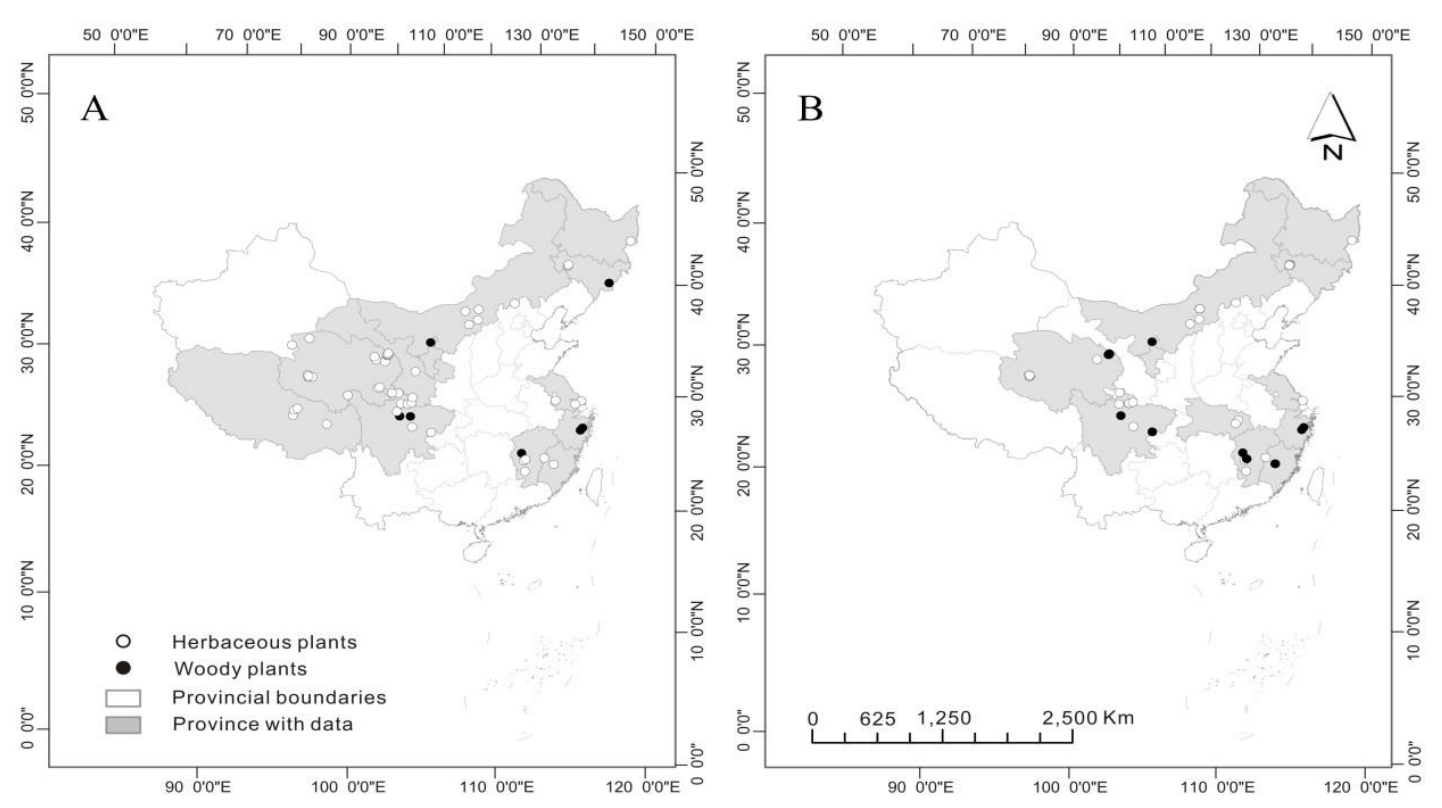

Figure 1. Study sites included in this meta-analysis across the whole of China: (A) Above-ground biomass, (B) Below-ground biomass. We grouped plant types by herbaceous plants (open circles) and woody plants (closed black circles). For detailed distribution information, please see the Supplementary Material (S6). 


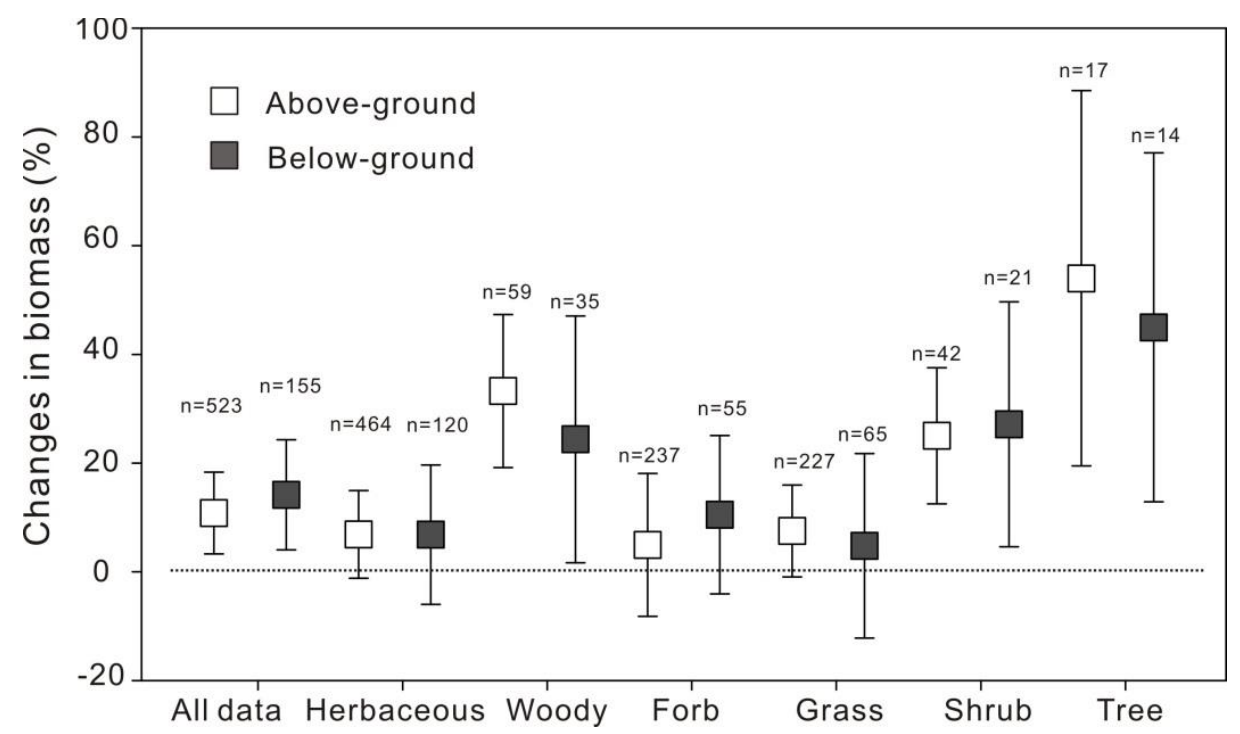

Figure 2. Responses of plant biomass (inverse-variance weights), above-ground biomass (AGB), and below-ground biomass (BGB), to warming as a percentage change relative to the control (\%) across plant functional types (PFTs). Changes in biomass values are means $\pm 95 \% \mathrm{CI}$ and the number of observations ( $n$ ) are shown near the bar.

\subsection{Relationships among Warming-Induced Biomass Responses and Their Driving Factors}

This study focused on plant and community biomass responses to experimental warming in field conditions across China. Large variations are found across those collected observations in warming magnitudes $\left(0.12 \sim 5.52{ }^{\circ} \mathrm{C}\right)$ and duration (0.2 15 year). Through the model selection process, we selected the best model out of a total of 32 models developed and presented in Table 1. Although considerable differences in environmental factors were recorded among the sample plots (Figure 1), including MAT (-5.3 23.5 $\left.{ }^{\circ} \mathrm{C}\right)$, MAP $(110 \sim 1900 \mathrm{~mm})$, elevation $(2 \sim 5000 \mathrm{~m})$, Latitude $\left(26 \sim 46^{\circ} \mathrm{N}\right)$, and Longitude $\left(90 \sim 132^{\circ} \mathrm{E}\right)$, no significant linear relations were found between these factors and biomass responses. On the contrary, our results supported experimental intensity as a significant driver for plant biomass variations (Table 1). Positive correlations were found between Delta $\mathrm{T}$ and AGB increase $(p<0.01)$. Meanwhile, both AGB and BGB showed positive responses with Warm ${ }_{D}$. A positive linear relation was found between Plant ${ }_{\mathrm{CA}}$ and plant biomass, and a greater increase was observed in $\mathrm{BGB}$ (slope $=0.17)$ than AGB (slope $=0.05)(p<0.01)$. In brief, experimental warming led to the general

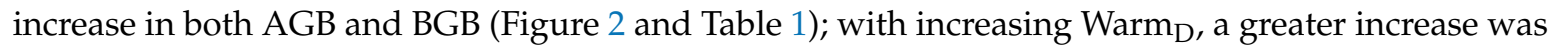
observed in BGB (slope $=0.19)(p<0.01)$. Additionally, we also could not ignore the effect due to phylogenetic reasons (Plant ${ }_{C A}$ ) (Table 1).

3.3. Varied Biomass Responses to Warming among Plant Types (Herbaceous versus Woody Species), and the Different Responses of the Plant Community and Its Dominant Species

Overall, plant biomass had positive responses with warming magnitudes and duration (Table 1), yet still with huge variations. These could be partly explained as the varied responses between plant types (herbaceous versus woody species) (Figure 2, Table 2), and the different responses of the plant community (Biomass $\mathrm{CW}$ ) and its dominant species (Biomass ${ }_{\mathrm{DS}}$ ) (Figures 3 and 4 ). Specifically, with increasing Plant $_{\mathrm{CA}}$ and Warm $\mathrm{D}_{\mathrm{D}}$, suppressed Biomass $\mathrm{CW}_{\mathrm{W}}$ was observed in both AGB $(p<0.01)$ and

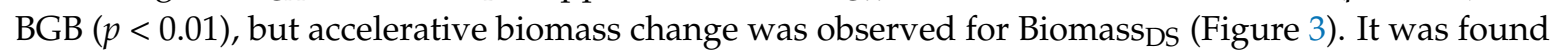
that dominant plants themselves with an older clade age could have more positive responses to warming. However, Biomass $\mathrm{CW}_{\mathrm{W}}$ would decrease. Additionally, positive relations have been found between warming treatment (Warm ${ }_{\mathrm{D}}$ and Delta ${ }_{\mathrm{T}}$ ) and biomass (AGB and BGB) in Biomass $\mathrm{CW}_{\mathrm{CW}}(p<0.01)$, but negative or no significant relations were found for Biomass ${ }_{\mathrm{DS}}$ (Figure 4). Moreover, we could 
not ignore the combined synergies between plant types and the possible different responses of the plant community and its dominant species (Table 2). All these results suggest that there would be trade-offs between Biomass $\mathrm{CW}_{\mathrm{W}}$ and Biomass ${ }_{\mathrm{DS}}$ facing a warming environment; meanwhile, herbaceous and woody species did not always have constant responses. As such, and also given the fact that woody data remain limited (Figure 2), more caution is needed in evaluating warming-induced shifts in interspecies correlation and the consequent vegetation responses; in particular, more research is still needed for Chinese forests.

Table 2. Generalized linear regression model was used to test whether plant types (herbaceous versus woody species), the different responses of the plant community and its dominant species, and the combined synergies would affect biomass accumulation patterns. Model-averaged coefficients, standard errors (SE), z-tests, and $p$-values for parameters are given.

\begin{tabular}{ccccccccc}
\hline & \multicolumn{3}{c}{ Above-Ground Biomass (AGB) } & \multicolumn{3}{c}{ Below-Ground Biomass (BGB) } \\
\cline { 2 - 9 } & Estimate & $\mathbf{S E}$ & $\mathbf{z}$ & $\boldsymbol{p}$ & Estimate & $\mathrm{SE}$ & $\mathbf{z}$ & $\boldsymbol{p}$ \\
\hline (Intercept) & 0.11 & 0.37 & 2.93 & $<0.01$ & 0.08 & 0.69 & 1.10 & 0.27 \\
Wood_or_not & 0.16 & 0.06 & 2.92 & $<0.01$ & 0.13 & 0.04 & 3.06 & $<0.01$ \\
Com_or_Sing & -0.24 & 0.01 & -25.78 & $<0.01$ & -0.14 & 0.11 & -1.26 & 0.21 \\
Woo:Com & 0.50 & 0.06 & 8.33 & $<0.01$ & 0.37 & 0.133 & 2.78 & $<0.01$ \\
\hline
\end{tabular}

Wood_or_not. herbaceous versus woody species; Com_or_Sing: Biomass ${ }_{\mathrm{CW}}$ vs. Biomass ${ }_{\mathrm{DS}}$; Woo:Com: the combined synergies between Wood_or_not and Com_or_Sing.
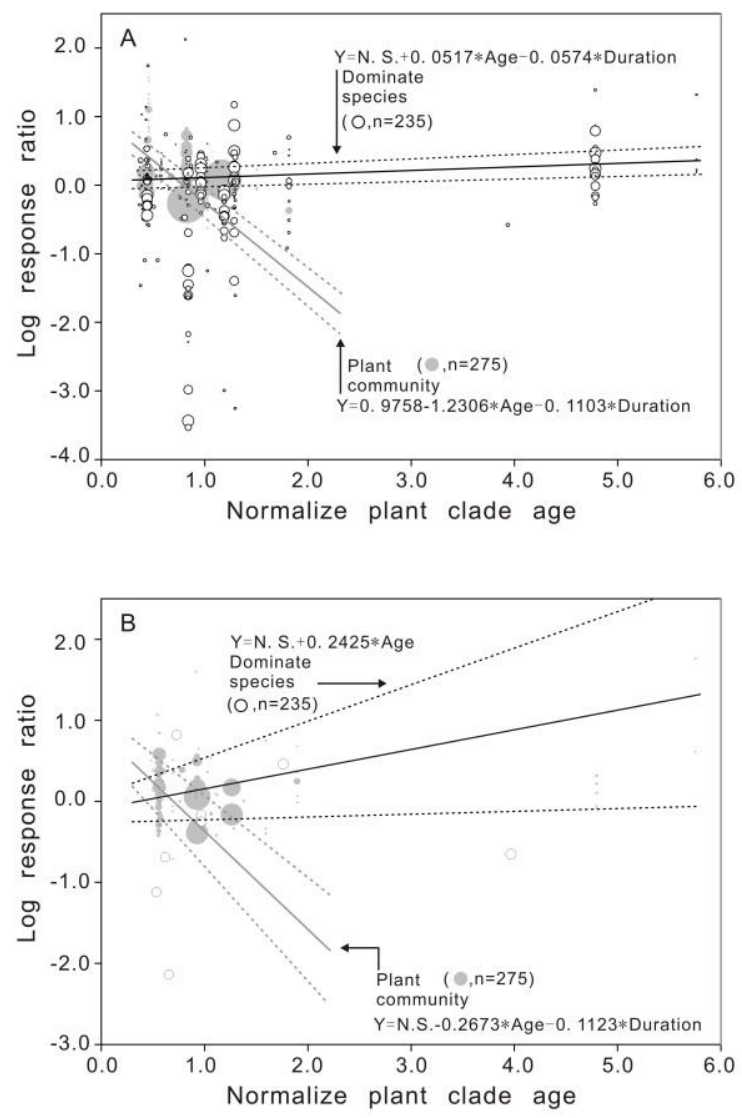

Figure 3. The effect of plant clade age (Plant ${ }_{C A}$ ) and warming duration (Warm $\left.{ }_{D}\right)$ on warming-induced biomass accumulation of the plant community (gray circle, Biomass $\mathrm{CW}_{\mathrm{CW}}$ ) and its dominant species (open circle, Biomass $\left.{ }_{D S}\right)$. The size of the circle indicated the difference across Warm ${ }_{D} \cdot(A)$ : Above-ground biomass (AGB); (B) Below-ground biomass (BGB). Corresponding equations showed the results of multiple mixed-effects meta-regression models, which considered Plant $\mathrm{CA}_{\mathrm{A}}$, Warm $\mathrm{D}_{\mathrm{D}}$, and plant biomass. N.S.: no significance in "Intercept" of the model $(p>0.05) ; n$ : the number of collected data. 

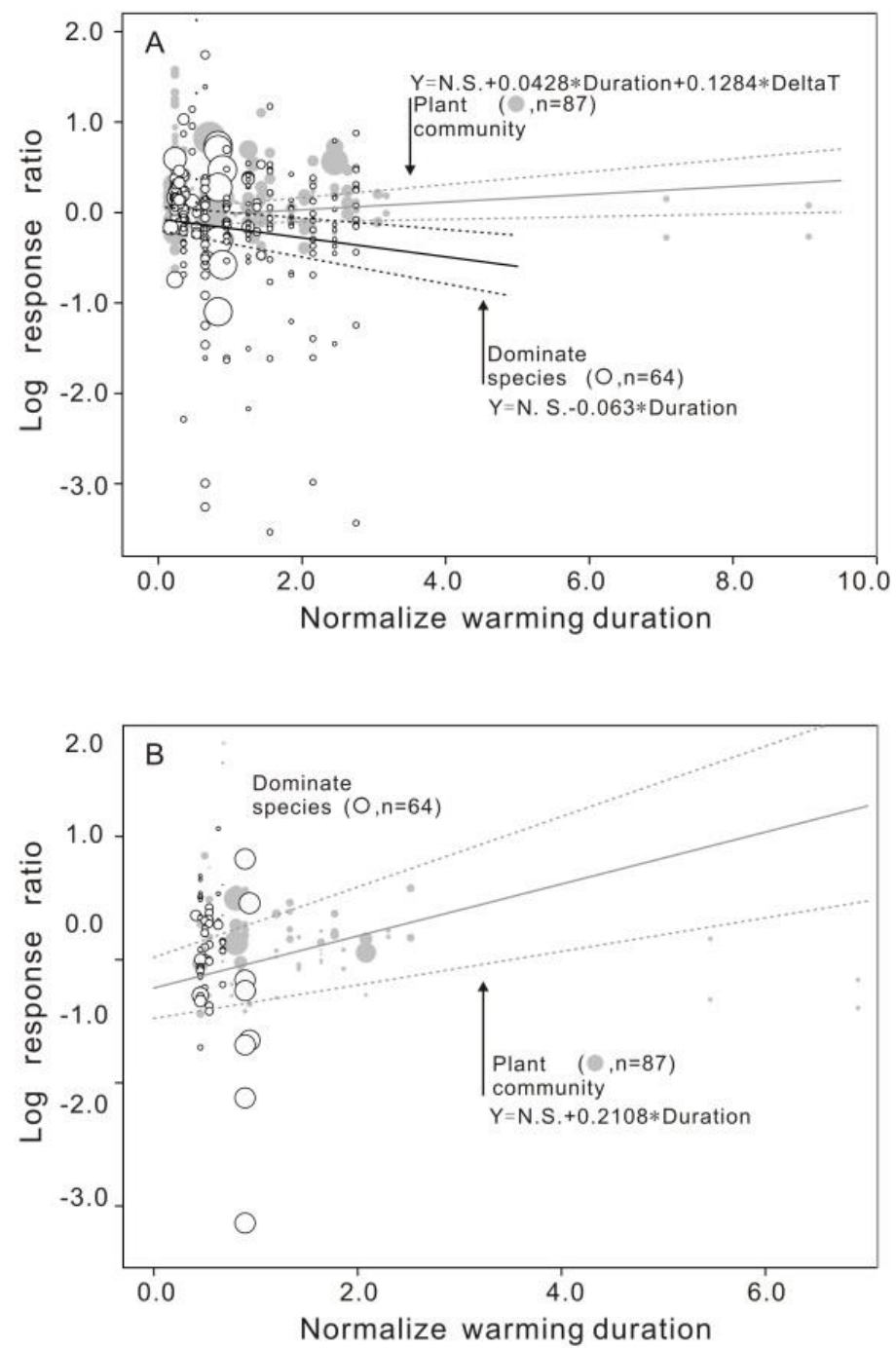

Figure 4. The effect of warming magnitudes $\left(\right.$ Delta $\left._{\mathrm{T}}\right)$ and warming duration (Warm $\mathrm{D}$ ) on warming-induced biomass accumulation of plant community (gray circle, Biomass ${ }_{\mathrm{CW}}$ ) and its dominant species (open circle, Biomass ${ }_{\mathrm{DS}}$ ). The size of the circle indicated the difference across Delta . (A): Above-ground biomass (AGB); (B): Below-ground biomass (BGB). Corresponding equations showed the results of multiple mixed-effects meta-regression models, which considered Delta $\mathrm{T}_{\mathrm{T}}, \mathrm{Warm}_{\mathrm{D}}$, and plant biomass. N.S.: no significance in "Intercept" of the model; $n$ : the number of collected data. In addition, we ignored the equation for BGB of dominant species, as that model was not significant for both "Intercept" and "Slope".

\subsection{More Caution Is Needed in Quantifying Warming-Induced Biomass Accumulation}

As mentioned above, Delta ${ }_{T}$, Warm ${ }_{D}$, Plant ${ }_{C A}$, and plant type are key drivers for biomass responses to warming. Therefore, we compared results from traditional meta-analyses and models updated to consider Warm ${ }_{D}$ and phylogeny. Regarding AGB, we found that cumulative effect sizes (all data) somewhat decreased after re-calculation was weighted by Delta ${ }_{\mathrm{T}}$ and Warm ${ }_{\mathrm{D}}$ (Figure 5, Default: +0.103 , with a $95 \%$ CI of $0.03 \sim 0.18$; Warming: +0.089 , with a $95 \%$ CI of $0.021 \sim 0.156$ ). In particular, effect sizes for Shrub decreased from 0.407 to 0.125 , and with a $95 \%$ CI, overlapped with zero. Moreover, significantly accelerative biomass growth was still observed for Tree after being weighted by Delta and Warm $_{\mathrm{D}}$ (Figure 5). Regarding BGB, re-calculated effect sizes (all data) presented insignificant change after warming (Figure 6, Default: +0.133 , with a 95\% CI of 0.034 0.231; Warming: +0.088 , with a $95 \%$ CI of $-0.009 \sim 0.184)$. Generally, BGB and AGB had similar trends, except the effect sizes of 
Grass, which increased after re-calculation (Figure 6, Default: +0.047 , with a 95\% CI of $-0.116 \sim 0.210$; Warming: +0.190 , with a $95 \%$ CI of $-0.004 \sim 0.383$ ). These results indicated that warming-induced biomass accumulation (Default in Figures 5 and 6 ) decreased when considering Delta ${ }_{T}$ and Warm ${ }_{D}$. Moreover, there were significant phylogenetic signals $(p<0.01)$. When we included plant phylogenetic information in the calculation model, all warming-induced increases of plant biomass, overall or for different PFTs (even including woody species), became not significant (Figures 5 and 6). All these results suggest again that when evaluating warming-induced vegetation responses in China, more consideration is needed regarding warming magnitudes, duration, and phylogeny-based responses. In addition, it is premature to speculate that elevated temperatures would lead to significant increases in plant biomass across different systems or overall for the whole of China.

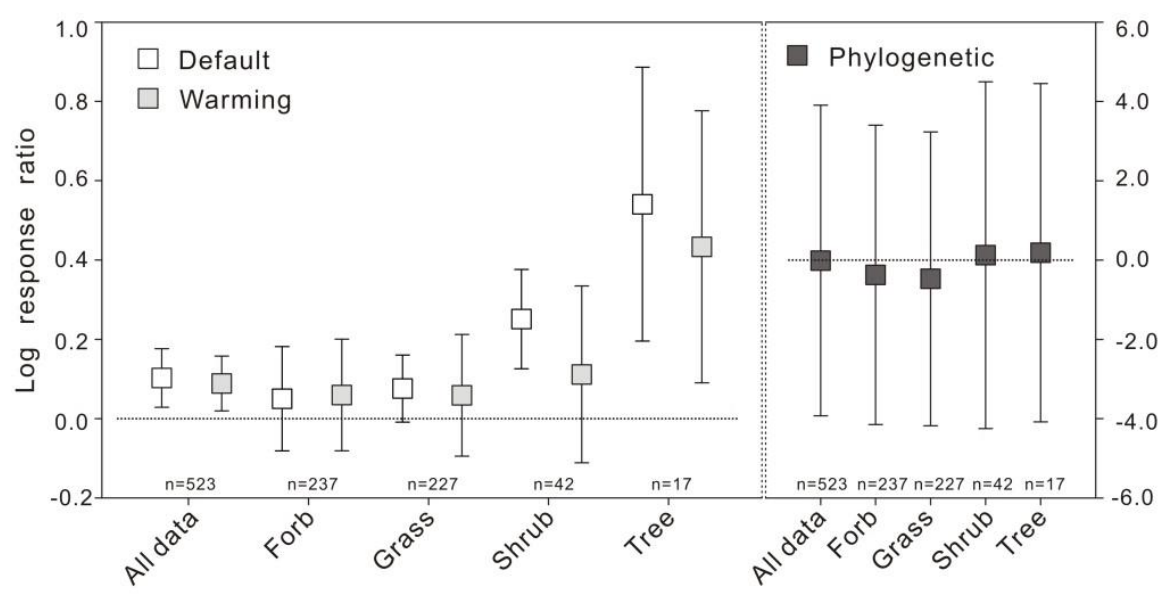

Figure 5. Responses of above-ground biomass (AGB) to warming as mean effect sizes $\pm 95 \% \mathrm{CI}$ across plant functional types (PFTs). The numbers ( $n$ ) of observations are shown near the bar. Default: mean effect sizes weighted by inverse-variance (traditional meta-analysis); Warming: mean effect sizes weighted by Delta $\mathrm{T}_{\mathrm{T}}$ and Warm $\mathrm{D}$ (Equation (4)); Phylogenetic: plant phylogenetic feature was included in the model.

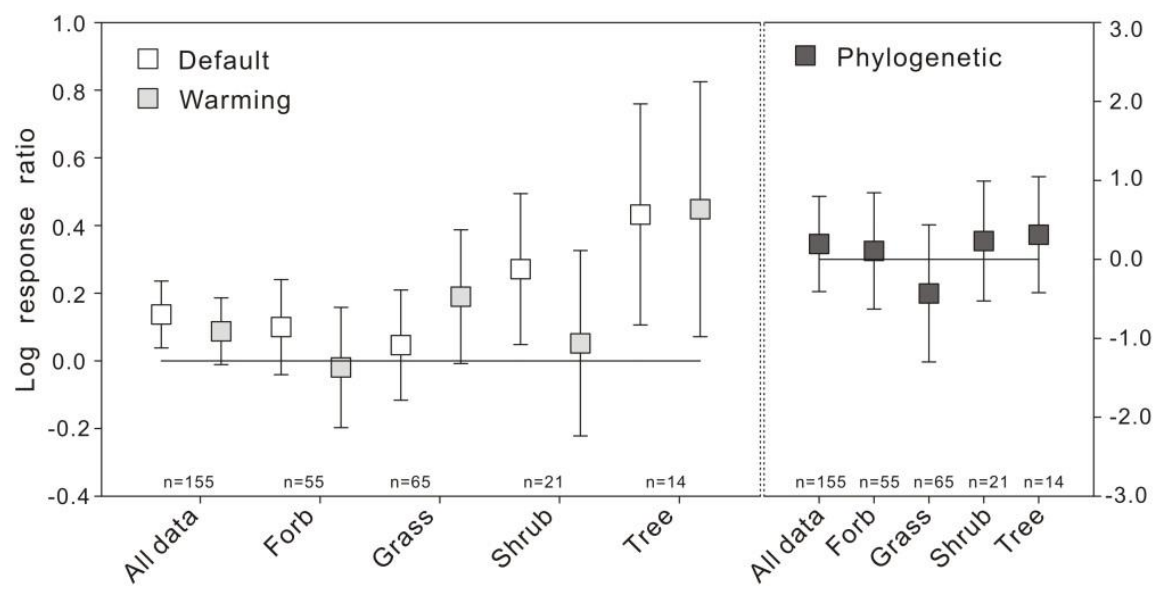

Figure 6. Responses of below-ground biomass (BGB) to warming as mean effect sizes $\pm 95 \%$ CI across plant functional types (PFTs). The numbers $(n)$ of observations are shown near the bar. Default: mean effect sizes weighted by inverse-variance (traditional meta-analysis); Warming: mean effect sizes weighted by Delta $\mathrm{T}_{\mathrm{T}}$ and Warm $_{\mathrm{D}}$ (Equation (4)); Phylogenetic: plant phylogenetic feature was included in the model.

\section{Discussion}

Overall, warming-induced biomass increases were observed (traditional approach), although there was no significant difference between AGB $(+10.8 \%)$ and BGB $(+14.2 \%)$, and there were still 
large variations within each group. Compared to previous meta-analyses, our results were similar to the global mean by Lin et al. (AGB: $+12.7 \%$; BGB: $13.0 \%$ ) [4], but they were smaller than the results from the Tibetan Plateau in China (AGB: +19.1\%; BGB: 26.7\%) [8]. As Lin et al. [4] mentioned in 2010, this difference could be explained by the inclusion of more data from low altitudes and latitudes in our analysis, since warming would have a stronger than average effect on alpine plants and tundra plants $[4,5,8]$.

Consistent with previous studies [4,9], biomass responses to warming were strongly dependent upon PFTs, and woody plants showed a greater response than herbaceous plants (Figure 1). Delta had a positive effect on AGB, and warming-induced biomass change could have quadratic responses with latitude and MAT (Table 1). Contrary to expectations [4], this study did not find a positive linear association between the plant biomass response to warming and MAP. Given that herbaceous plants appeared to be unaffected by MAP [4], the greater number of herbaceous species data included in the analysis, rather than woody species data, might partially explain this result. Overall, these results across China mostly match global trends of warming-induced biomass patterns (based on a traditional meta-analysis approach) across latitude, MAT, MAP, and PFTs.

Still, there are some results that have not been previously described, regarding plant clade age (phylogenetic history), Warm ${ }_{\mathrm{D}}$, and the different responses between community-level biomass and a community's dominant species. Remarkably, a positive correlation is observed between plant clade age and warming-induced responses in dominant species for both AGB and BGB (Figures 2 and 3). The results could be explained by the fact that the woody species included in our analysis, in particular gymnosperm with a high clade age [20], often have positive responses with warmer climates [9], which could partially explain this trend. However, this does not mean that ancient plants would benefit more from warming, when we consider examples from lichens [22] and relicts [23]. Because the current collected data all over China is still limited, we are lacking not only data regarding herbs, trees, and shrubs, but we also could not collect through publications data regarding lichens, lianas, and other plant forms. Consequently, we cannot analyse the phylogenetic relationships and clustering patterns regarding woody and non-woody species in China following the method of Willis et al. [15]. Yet, in any case, consistent with Willis' work [15], our findings convincingly suggest that the phylogenetic feature is a key factor affecting warming-induced plant responses, the study of which is still limited in China. Meanwhile, contrary to previous studies [4,18], a positive correlation is observed between $W a_{D}$ and warming-induced responses at the community-level (Figure 3). We suggest that this finding could reflect the natural state of vascular plants better, since only field experiments were included in our analysis.

Moreover, different response patterns were notably found between the plant community and its corresponding dominant species (Figure 3). Although an elevated temperature could lead to a general increase in biomass at the community-level, AGB of the dominant species showed a declining trend along warming duration. This finding broadly and partially supports the work of Ma et al. [24], which indicated that ongoing and future climate change may alter the stability properties of ecological communities. Other previous works have also mentioned that warming could lead to a decline in species richness [18], and potential alien species invasion [25]. Taking all of the above into consideration, we are concerned that although warming would lead to temporary and compensatory biomass increases at the community-level, other potential effects would hinder the ability to provide long-term ecosystem services for C stock, especially in grassland ecosystems [26,27]. In general, Warm ${ }_{D}$ and plant features, i.e., phylogeny, therefore seems to need further consideration when estimating warming-induced biomass responses [8,11,12,28].

When we re-calculated warming-induced biomass change weighted by Delta $\mathrm{T}_{\mathrm{T}}$ and $\mathrm{Warm}_{\mathrm{D}}$ (Equation (4)), less accelerative AGB growth was observed compared to the result weighted by inverse-variance (Figure 5, Default: +0.103 , with a 95\% CI of 0.03 0.18; Warming: +0.089 , with a $95 \%$ CI of 0.021 0.156). There even seemed to be no significant accelerative change in BGB after re-calculations (Figure 6, Default: +0.133 , with a $95 \%$ CI of $0.034 \sim 0.231$; Warming: +0.088 , with a 95\% 
CI of $-0.009 \sim 0.184)$. In all, we found similar trends to Fu et al. (2015), which focused on plants on the Tibetan Plateau [8]. Meanwhile, significant accelerative AGB and BGB changes were still notably present for tree species in the re-calculated results (Figures 5 and 6). By now, almost all meta-analyses have suggested that trees would benefit more through global warming than herbs $[4,8,9]$, yet we remain concerned that the comparison of herbaceous and woody species should depend on time scales and the age of the woody species. Taking heartwood as an example: It represents a considerable part of trees' AGB, and will increase with age; whereas the AGB of herbaceous species is renewed every year, which could decrease relative biomass increments; and these would consequently affect the final calculated response pattern between the two types. However, to date, both this research and previous meta-analyses work still cannot address this issue, which needs further study.

Furthermore, decreases in accumulative effect size magnitudes after incorporating phylogenetic information were associated with larger phylogenies and those with stronger phylogenetic signals (Figures 5 and 6). Although these did not change trend estimates, they increased the $\mathrm{CI}$ of the overall mean natural logarithm of RRs and made the mean estimates statistically insignificant (Figures 5 and 6). We note that the overall means produced by phylogenetic models could represent an ancestral value; similar patterns were also found by Chamberlain et al. [7] after they re-analyzed 30 published meta-analyses worldwide, so it is perhaps not surprising that such estimates have higher degrees of uncertainty. On the other hand, these phylogenetic outcomes could be influenced by both phylogeny balance and the distribution of internal nodes between the root and its tips [10], which would lead to consequent uncertainty in our study. We believe that the incorporation of phylogenetic information in ecological meta-analyses is important, and traditional meta-analysis (inverse-variance weights) could have overestimated warming-induced biomass increases (Figures 5 and 6).

Last but not least important, regional (and ecosystem-based) biases remain and cannot be ignored in our research. A large number of works included here focus on plateaus and grasslands, where the low temperatures could be the principal limiting factor; whereas under other conditions, where growth is limited by heat or drought, our accumulative biomass response would be changed. Meanwhile, field-based experiments concerning woody plants are still limited, especially for trees; this reduces the credible projection of our research regarding the climate-terrestrial $C$ response in China. Moreover, research should also be undertaken to investigate the responses of special plants like relic species [23,29], invasive species [25,30], agroforestry trees [31,32], and plants living in special geological environments [17,33], often regarded in the investigation of ecosystem services for humanity, but for which field-based warming experiments are still limited. Finally, as we have mentioned, plant communities and their dominant species do not always show a constant response, and so to develop a full picture of warming-induced responses of plant biomass and $C$ sequestration, additional long-term warming experiments regarding community stability [24], interspecific relations [30], functional diversity and evolution $[13,16,18]$, etc., will be needed.

\section{Conclusions}

This present research was undertaken to understand the general pattern of plant biomass responses to warming in China. Based on traditional meta-analyses, we found biomass response patterns similar to those in global studies. Contrary to previous results, we found positive relations between biomass increase and warming duration. Plant clade age (phylogenetic history) was a key factor in driving warming-induced biomass accumulation. Furthermore, the combined synergies between plant types and the possible different responses of the plant community and its dominant species cannot be ignored; this is a key factor which could lead to variations in biomass responses.

The most obvious finding to emerge from this study is that traditional meta-analysis could have overestimated the warming-induced biomass increase in China, which seems to be not significant after incorporating warming duration and phylogenetic information into re-calculations. Meanwhile, field-based experiments concerning woody plants are still limited; especially lacking is research 
regarding observations on the whole community's level (dominant woody species versus rare woody and herbaceous species).

Therefore, regarding the aspect of methodology, to reflect warming-induced responses as naturally as possible, further long-term warming experiments regarding phylogeny-based responses and the trade-off between the dominant species and its corresponding community will be needed. At the same time, regarding re-vegetation under warmer climates, first, it remains premature to speculate that woody plants have greater biomass increases than herbaceous plants in response to elevated temperatures. Second, we suggest flexible sub-regional protection strategies for ecosystem management. Meanwhile, not only dominant species, but rare species and their subsequent interspecies relations, should be incorporated into re-vegetation as well, especially regarding woody plants and forests.

Supplementary Materials: The following materials are available online http:/ / www.mdpi.com/1999-4907/9/ 10/619/s1. S1: Search strategy reference. S2: Data sources and reference list. S3: The distribution of study sites included in this meta-analysis. S4: Phylogenetic relationships between 108 plant species included in this meta-analysis. S5: Main R packages and the corresponding codes used in our research. S6: Detailed coordinate information regarding Woody species and No-woody observations included in this meta-analyses.

Author Contributions: Both K.Y. and H.Y. have equally contributed to this manuscript. K.Y. and J.X. conceived and designed the research; K.Y. and H.Y. performed the data collection and wrote the draft; S.Z. supported data analysis for the whole manuscript; Y.L. analyzed phylogenetic information and drew the composite phylogeny in S4; D.Z. and Z.W. supported the drawing of figures; S.R. contributed to the writing of this paper.

Funding: This research was financially supported by Projects of International Cooperation and Exchanges, NSFC (41661144001); Fundamental Research Funds for the Chinese Academy of Sciences' Frontier Science Key Project (QYZDY-SSWSMC014); Federal Ministry for Economic Cooperation and Development, Germany (\#13.1432.7-001.00); Yunnan Postdoctoral Science Foundation (Y732081261); Provincial Innovation Group for Farmland Non-pollution Production, Yunnan Agricultural University (2017HC015); and National Natural Science Foundation of China (41807524).

Acknowledgments: We thank Li Mingiiu, former Communications Assistant at the World Agroforestry Centre, East and Central Asia, for providing English editing. Meanwhile, we would also like to thank Xishuangbanna Tropical Botanical Garden, Chinese Academy of Sciences, for organizing the Meta-analysis Workshop in Ecology and Conservation in 2016, during which meta-analysis and data synthesis theory and methods were learnt and extensively practiced.

Conflicts of Interest: The authors declare no conflict of interest.

\section{References}

1. Luo, Y. Terrestrial carbon-cycle feedback to climate warming. Annu. Rev. Ecol. Syst. 2007, 38, 683-712. [CrossRef]

2. Cox, P.M.; Betts, R.A.; Jones, C.D.; Spall, S.A.; Totterdell, I.J. Acceleration of global warming due to carbon-cycle feedbacks in a coupled climate model. Nature 2000, 408, 184-187. [CrossRef] [PubMed]

3. Moore, P.T.; Derose, R.J.; Long, J.N.; Miegroet, H.V. Using silviculture to influence carbon sequestration in southern appalachian spruce-fir forests. Forests 2012, 3, 300-316. [CrossRef]

4. Lin, D.; Xia, J.; Wan, S. Climate warming and biomass accumulation of terrestrial plants: A meta-analysis. New Phytol. 2010, 188, 187-198. [CrossRef] [PubMed]

5. Walker, M.D.; Wahren, C.H.; Hollister, R.D.; Henry, G.H.; Ahlquist, L.E.; Alatalo, J.M.; Bretharte, M.S.; Calef, M.P.; Callaghan, T.V.; Carroll, A.B. Plant community responses to experimental warming across the tundra biome. Proc. Natl. Acad. Sci. USA 2006, 103, 1342-1346. [CrossRef] [PubMed]

6. Mäkiranta, P.; Laiho, R.; Mehtätalo, L.; Straková, P.; Sormunen, J.; Minkkinen, K.; Penttilä, T.; Fritze, H.; Tuittila, E.S. Responses of phenology and biomass production of boreal fens to climate warming under different water-table level regimes. Glob. Chang. Biol. 2017, 24, 944-956. [CrossRef] [PubMed]

7. Nakagawa, S.; Poulin, R.; Mengersen, K.; Reinhold, K.; Engqvist, L.; Lagisz, M.; Senior, A.M. Meta-analysis of variation: Ecological and evolutionary applications and beyond. Methods Ecol. Evol. 2015, 6, 143-152. [CrossRef] 
8. Fu, G.; Shen, Z.X.; Sun, W.; Zhong, Z.M.; Zhang, X.Z.; Zhou, Y.T. A meta-analysis of the effects of experimental warming on plant physiology and growth on the Tibetan plateau. J. Plant Growth Regul. 2015, 34, 57-65. [CrossRef]

9. Yuan, Y.; Ge, L.; Yang, H.; Ren, W. A meta-analysis of experimental warming effects on woody plant growth and photosynthesis in forests. J. For. Res. 2018, 29, 1-7. [CrossRef]

10. Chamberlain, S.A.; Hovick, S.M.; Dibble, C.J.; Rasmussen, N.L.; Van Allen, B.G.; Maitner, B.S.; Ahern, J.R.; Bell-Dereske, L.P.; Roy, C.L.; Meza-Lopez, M. Does phylogeny matter? Assessing the impact of phylogenetic information in ecological meta-analysis. Ecol. Lett. 2012, 15, 627-636. [CrossRef] [PubMed]

11. Adams, D.C. Phylogenetic meta-analysis. Evolution 2008, 62, 567-572. [CrossRef] [PubMed]

12. Xie, X.F.; Hu, Y.K.; Pan, X.; Liu, F.H.; Song, Y.B.; Dong, M. Biomass allocation of stoloniferous and rhizomatous plant in response to resource availability: A phylogenetic meta-analysis. Front Plant Sci. 2016, 7, 603. [CrossRef] [PubMed]

13. Cantarel, A.A.M.; Bloor, J.M.G.; Soussana, J.F. Four years of simulated climate change reduces above-ground productivity and alters functional diversity in a grassland ecosystem. J. Veg. Sci. 2013, 24, 113-126. [CrossRef]

14. Crowther, T.W.; Todd-Brown, K.E.; Rowe, C.W.; Wieder, W.R.; Carey, J.C.; Machmuller, M.B.; Snoek, B.L.; Fang, S.; Zhou, G.; Allison, S.D. Quantifying global soil carbon losses in response to warming. Nature 2016, 540, 104-108. [CrossRef] [PubMed]

15. Willis, C.G.; Ruhfel, B.; Primack, R.B.; Miller-Rushing, A.J.; Davis, C.C. Phylogenetic patterns of species loss in thoreau's woods are driven by climate change. Proc. Natl. Acad. Sci. USA 2008, 105, 17029-17033. [CrossRef] [PubMed]

16. Seidl, R.; Thom, D.; Kautz, M.; Martinbenito, D.; Peltoniemi, M.; Vacchiano, G.; Wild, J.; Ascoli, D.; Petr, M.; Honkaniemi, J. Forest disturbances under climate change. Nat. Clim. Chang. 2017, 7, 395-402. [CrossRef] [PubMed]

17. Yan, K.; Ranjitkar, S.; Zhai, D.; Li, Y.; Yang, J. Current re-vegetation patterns and restoration issues in degraded geological phosphorus-rich mountain areas: A synthetic analysis of central Yunnan, SW China. Plant Divers. 2017, 39, 140-148. [CrossRef] [PubMed]

18. Gruner, D.S.; Bracken, M.E.S.; Berger, S.A.; Eriksson, B.K.; Gamfeldt, L.; Matthiessen, B.; Moorthi, S.; Sommer, U.; Hillebrand, H. Effects of experimental warming on biodiversity depend on ecosystem type and local species composition. Oikos 2017, 126, 8-17. [CrossRef]

19. Viechtbauer, W. Metafor: Meta-Analysis Package for R. R Package Version 1.4-0. Available online: http:/ /CRAN.R-project.org / package=metafor (accessed on 2 October 2018).

20. Qian, H.; Jin, Y. An updated megaphylogeny of plants, a tool for generating plant phylogenies and an analysis of phylogenetic community structure. J. Plant Ecol. 2016, 9, 233-239. [CrossRef]

21. Calcagno, V. Glmulti: Model Selection and Multimodel Inference Made Easy. 2013. Available online: https:/ / rdrr.io/cran/glmulti/ (accessed on 2 October 2018).

22. Cornelissen, J.H.C.; Callaghan, T.V.; Alatalo, J.M.; Michelsen, A.; Graglia, E.; Hartley, A.E.; Hik, D.S.; Hobbie, S.E.; Robinson, C.H.; Henry, G.H.R. Global change and arctic ecosystems: Is lichen decline a function of increases in vascular plant biomass? J. Ecol. 2001, 89, 984-994. [CrossRef]

23. Hampe, A.; Jump, A.S. Climate relicts: Past, present, future. Annu. Rev. Ecol. Syst. 2011, 42, $313-333$. [CrossRef]

24. Ma, Z.; Liu, H.; Mi, Z.; Zhang, Z.; Wang, Y.; Xu, W.; Jiang, L.; He, J.S. Climate warming reduces the temporal stability of plant community biomass production. Nat. Commun. 2017, 8, 15378. [CrossRef] [PubMed]

25. Kathiresan, R. Effect of Global Warming on Invasion of Alien Plants in Asia. Available online: http:/ / citeseerx.ist.psu.edu/viewdoc/download?doi=10.1.1.570.2741\&rep=rep1\&type=pdf (accessed on 2 October 2018).

26. Walker, T.N.; Garnett, M.H.; Ward, S.E.; Oakley, S.; Bardgett, R.D.; Ostle, N.J. Vascular plants promote ancient peatland carbon loss with climate warming. Glob. Chang. Biol. 2016, 22, 1880-1889. [CrossRef] [PubMed]

27. Boeck, H.J.D.; Lemmens, C.M.H.M.; Zavalloni, C.; Gielen, B.; Malchair, S.; Carnol, M.; Merckx, R.; Berge, J.V.D.; Ceulemans, R.; Nijs, I. Biomass production in experimental grasslands of different species richness during three years of climate warming. Biogeosci. Discuss. 2007, 4, 585-594. [CrossRef]

28. Guo, L.; Cheng, J.; Luedeling, E.; Koerner, S.E.; He, J.S.; Xu, J.; Gang, C.; Li, W.; Luo, R.; Peng, C. Critical climate periods for grassland productivity on China's loess plateau. Agric. For. Meteorol. 2017, 233, 101-109. [CrossRef] 
29. Tang, C.Q.; Dong, Y.F.; Herrandomoraira, S.; Matsui, T.; Ohashi, H.; He, L.Y.; Nakao, K.; Tanaka, N.; Tomita, M.; Li, X.S. Potential effects of climate change on geographic distribution of the tertiary relict tree species Davidia involucrata in China. Sci. Rep. 2017, 7, 43822. [CrossRef] [PubMed]

30. Wu, H.; Ismail, M.; Ding, J. Global warming increases the interspecific competitiveness of the invasive plant alligator weed, Alternanthera philoxeroides. Sci. Total Environ. 2016, 575, 1415-1422. [CrossRef] [PubMed]

31. Jaradat, A.A. Genetic resources of energy crops: Biological systems to combat climate change. Aust. J. Crop Sci. 2010, 4, 309-323.

32. Shrestha, B.; Chang, S.; Bork, E.; Carlyle, C. Enrichment planting and soil amendments enhance carbon sequestration and reduce greenhouse gas emissions in agroforestry systems: A review. Forests 2018, 9, 369. [CrossRef]

33. Yan, K.; Duan, C.; Fu, D.; Li, J.; Wong, M.H.G.; Qian, L.; Tian, Y. Leaf nitrogen and phosphorus stoichiometry of plant communities in geochemically phosphorus-enriched soils in a subtropical mountainous region, SW China. Environ. Earth Sci. 2015, 74, 3867-3876. [CrossRef]

(C) 2018 by the authors. Licensee MDPI, Basel, Switzerland. This article is an open access article distributed under the terms and conditions of the Creative Commons Attribution (CC BY) license (http://creativecommons.org/licenses/by/4.0/). 